Article

\title{
Effect of Industrial Heat Treatment and Barrel Finishing on the Mechanical Performance of Ti6Al4V Processed by Selective Laser Melting
}

\author{
Filippo Nalli ${ }^{1}$, Luana Bottini ${ }^{2, *}$, Alberto Boschetto ${ }^{2}{ }^{\mathbb{C}}$, Luca Cortese ${ }^{2}$ and Francesco Veniali ${ }^{2}$ \\ 1 Faculty of Science and Technology, Free University of Bozen-Bolzano, Piazza Università 1, 39100 Bolzano, \\ Italy; filippo.nalli@natec.unibz.it \\ 2 Department of Mechanical and Aerospace Engineering, Sapienza University of Rome, Via Eudossiana 18, \\ 00184 Roma, Italy; alberto.boschetto@uniroma1.it (A.B.); luca.cortese@uniroma1.it (L.C.); \\ francesco.veniali@uniroma1.it (F.V.) \\ * Correspondence: luana.bottini@uniroma1.it
}

Received: 19 February 2020; Accepted: 20 March 2020; Published: 27 March 2020

check for updates

\begin{abstract}
Additive manufacturing is now capable of delivering high-quality, complex-shaped metallic components. The titanium alloy Ti6Al4V is an example of a printable metal being broadly used for advanced structural applications. A sound characterization of static mechanical properties of additively manufactured material is crucial for its proper application, and here specifically for Ti6Al4V. This includes a complete understanding of the influence of postprocess treatment on the material behavior, which has not been reached yet. In the present paper, the postprocess effects of surface finish and heat treatment on the mechanical performance of Ti6Al4V after selective laser melting were investigated. Some samples were subjected to barrel finishing at two different intensities, while different sets of specimens underwent several thermal cycles. As a reference, a control group of specimens was included, which did not undergo any postprocessing. The treatments were selected to be effective and easy to perform, being suitable for real industrial applications. Tensile tests were performed on all the samples, to obtain yield stress, ultimate tensile strength and elongation at fracture. The area reduction of the barrel-finished samples, after being tested, was measured by using a 3D scanner, as a further indication of ductility. Experimental results are reported and discussed, highlighting the effect of postprocessing treatments on the mechanical response. We then propose the optimal postprocessing procedure to enhance ductility without compromising strength, for structures manufactured from Ti6Al4V with selective laser melting.
\end{abstract}

Keywords: selective laser melting; additive manufacturing; Ti6Al4V; barrel finishing; heat treatment; tensile test

\section{Introduction}

Additive manufacturing (AM) technologies are becoming widespread thanks to their promising ability to manufacture nearly any complex shape. The metal additive technologies are extremely attractive, being able to produce structural components, made of the typical metal alloys used in industrial applications. There is a large number of AM methods for metal [1], and such methods can be categorized largely into two groups [2]: Directed Energy Deposition and Powder Bed Fusion. The former is characterized by large process complexity and requires a careful design of the part in order to obtain complex shapes with satisfactory accuracy, thus putting the Directed Energy Deposition at a great disadvantage with respect to powder bed methods. Within the latter category, selective laser melting (SLM), also known as direct metal laser sintering (DMLS), deposited by EOS, has the ability to produce highly complex-shaped components with relative ease. It is used in several 
manufacturing areas, ranging from automotive to biomedical, due to its suitability to manufacture light structures, optimizing the material usage. In such a scenario, a complete understanding of the mechanical performance of SLM-manufactured parts is crucial, due to the not redundant nature of the AM fabricated structures. The titanium alloy Ti6Al4V is one of the most employed materials in SLM technology and has the following attractive features: high strength, low density, excellent corrosion resistance and biocompatibility [3]. Ti6 Al4V is a commonly studied alloy, and investigations include those looking at microstructure [4,5], high cycle fatigue [6], static mechanical properties and ductility [7].

Traditional manufacturing processes of Ti6Al4V rely on forging, casting and rolling of bulk feedstock material, followed by machining to final shape and dimensions. These processes suffer disadvantages, such as poor machinability of Ti6Al4V, as well as high material waste and energy consumption [8,9]. These have begun to steer the industry toward SLM technology. Manufacturing with SLM affects the microstructure in a different way, in respect to the traditional manufacturing processes. Because of the high cooling rate, the Ti6Al4V microstructure mainly consists of fine non-equilibrium hcp martensite $\alpha^{\prime}$-phase. As a result, the tensile strength of the SLM part is higher than that of hot-worked parts, whereas the ductility is lower [10]. In addition, high residual stress usually occurs. A postprocessing heat treatment can increase ductility through the transformation of the metastable martensite into a biphasic $\alpha-\beta$ matrix, resulting in a reduction in strength [11]. Researchers have made great efforts in balancing strength and ductility within SLM fabrication of Ti6Al4V. In [12], the ductility was improved by increasing the baseplate temperature at $570{ }^{\circ} \mathrm{C}$, resulting in less residual stress. In [13], a double-scanning at a high energy density was employed to obtain fine lamellar $\alpha+\beta$ microstructure. Although the obtained material performances resulted in improved mechanical behavior, these strategies are not suitable for industrial production because of their lower process efficiency. Hence, the balancing between strength and ductility is to be achieved by subsequent thermal treatment. Depending upon the final requirements, the SLM parts are usually subjected to Hot Isostatic Pressing (HIP) and/or heat-treatment operation [14]. The HIP reduces the risk of undesirable porosity and breaks down columnar prior- $\beta$ grains parallel to the stratification direction, giving a more homogeneous behavior. Recently, most of the efforts aiming to select the best processing parameter set focused on the relative density and isotropy improving. The Ti6Al4V relative density was improved to 99.99\% [15]. Aging thermal treatments are currently the most diffused ways to balance strength and ductility: In [16] and [17], specific heat treatments for SLM Ti6A14V are mentioned. Nevertheless, the literature mainly focuses on residual stresses, microstructure evolution and fatigue resistance.

The parts manufactured by SLM are prone to a significant amount of induced residual stresses because of the high temperature gradients involved in the process: This phenomenon is amplified in the case of Ti6Al4V, due to its poor thermal conductivity. Thus, residual stress increases with the increasing number of layers [18].

Moreover, the scan strategy was proven to have a great influence on the residual stresses: The authors of [19] observed the correlation between the scan length and the residual stresses intensity, while [20] observed that residual stresses are larger along the scan direction than the perpendicular one, due to the larger thermal gradient. Since residual stresses originate from thermal gradients, the typical way to relieve them after the SLM process is a high-temperature stress-relief heat treatment [21].

The fatigue properties of as-built Ti6Al4V are similar to those of cast and wrought material, even without a HIP treatment [14]. Obviously, the fatigue life of AM parts increases when the surface-finishing level is enhanced, since the fatigue is a surface-induced critical phenomenon; then AM components need surface-finishing operations before service [22].

Thus, the low surface quality is one of the major challenges for AM industrialization. Milling and sandblasting are common solutions, but they have some drawbacks: SLM products typically have complex geometry; thus, the geometry freedom is lost when a machining toolpath must be planned. Meanwhile, sandblasting has lower repeatability and surface-finishing accuracy, being a manual operation that depends on the operator's skills. 
In such a scenario the barrel finishing (BF), which belongs to the family of mass-finishing technology, showed improvements of the mechanical performance of SLM parts [23]. It is typically used for finishing operations, from radiusing and deburring to very fine finishing. This technique consists in loading a charge composed by the components to be finished, media, water and compound within a rotating barrel: The relative motion between the charge components permits the micro-removal of the material performing the finishing operation [24]. The fixturing of the parts during the process is not necessary and therefore it is suitable for components in a variety of sizes, shapes and materials. Moreover, it requires a low investment cost, as well as very low maintenance costs [25]. For these characteristics, it is suitable for the finishing of AM parts [26]. The abrasive action is generated by the rotation of the barrel: As the barrel rotates, the charge is moved upward, until the force of gravity overcomes the tendency of the mass to stick together, and a layer slides down [27]. Depending on the filling and the rotational speed, six motions take place: sliding, slumping, rolling, cascading, cataracting and centrifuging [28]. Only two of these motions, i.e., rolling and cascading, permit a continuous flow, in the form of avalanches, providing the desired soft mechanical action of BF. Hence, adequate process parameters must be chosen. No theoretical model can help in this step, because the process parameters strictly depend upon the charge characteristics. The different motions can be described through the Bed Behavior (BB) diagram which is a map of the attainable motions as a function of the filling percentage and the rotational speed [28]. This BB diagram must be developed experimentally for each charge.

The present study aims to quantify the improvements on the static mechanical properties of SLM Ti6Al4V parts achievable with thermal treatments and BF finishing operation, thus acting both on residual stresses and surface finish quality levels. The specimens were fabricated in three different directions: vertical, horizontal and diagonal. A subset of specimens was subjected to heat treatment with several combinations of temperatures and durations, while another subset underwent BF at various intensities; a third reference subset was not postprocessed for a control group. All samples underwent tensile tests, to compare the resulting overall mechanical performance and material ductility.

\section{Materials and Methods}

Ti6Al4V is widely used in a broad range of different applications, ranging from use as turbine blades in the aerospace industry, to prostheses in the biomedical industry. The employed samples were fabricated via an EOS M290 machine equipped with an Ytterbium laser with a maximum power of $400 \mathrm{~W}$ and a building space of $250 \times 250 \times 325 \mathrm{~mm}^{3}$. The SLM technology implies that a laser scans the surface of a powder bed, locally melting the powder alloy, realizing a solid layer when cooling down. The building plate that contains the powder bed shifts down, and a new layer of metallic powder is spread on the top of the just-solidified metal, and the process goes on, building the component in a bottom-up manner, layer upon layer. The employed Ti6Al4V powder was supplied by EOS GmbH, and its chemical composition is reported in Table 1.

Table 1. Chemical composition of Ti6Al4V powder (wt.\%).

\begin{tabular}{cccccccccc}
\hline Al & $\mathbf{V}$ & $\mathbf{O}$ & $\mathbf{N}$ & $\mathbf{C}$ & $\mathbf{H}$ & $\mathbf{F e}$ & $\mathbf{Y}$ & $\mathbf{T i}$ & Other \\
\hline $5.50-6.75$ & $3.50-4.50$ & 0.20 & 0.05 & 0.08 & 0.015 & 0.30 & 0.005 & Bal & $0.10 \mathrm{Max}$ \\
\hline
\end{tabular}

In Figure 1, a SEM image of the used powders and the granulometry distribution measured by the laser diffraction granulometer Mastersizer 2000 are reported. The particles have a spheroidal shape, and $d_{10}, d_{50}$ and $d_{90}$ are 23.62, 37.69 and $59.11 \mu \mathrm{m}$, respectively, according to the material datasheet [29]. 

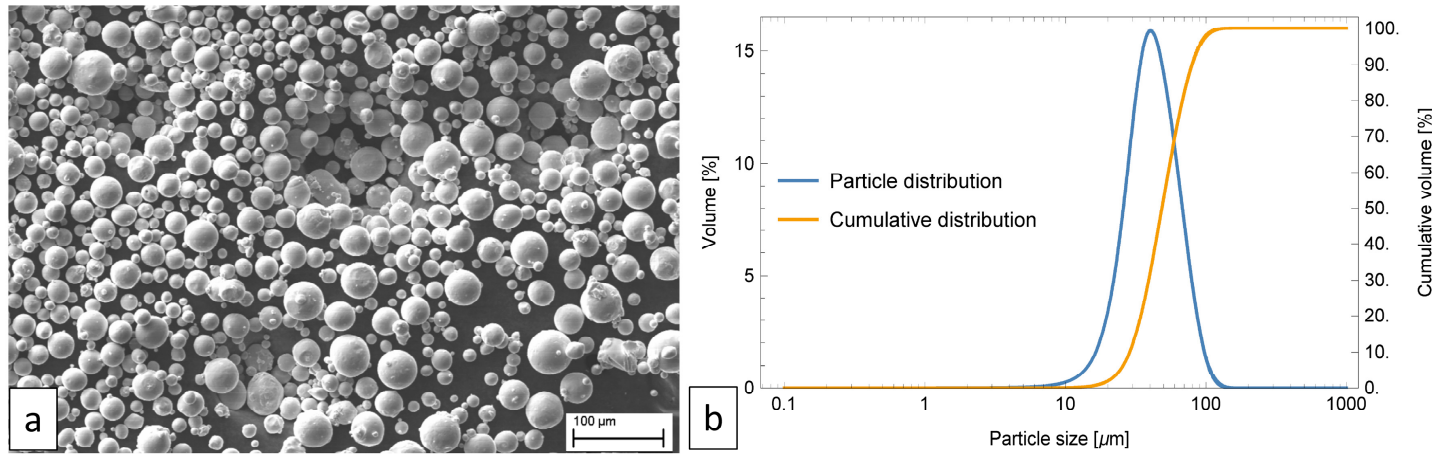

Figure 1. (a) SEM image of Ti6Al4V powders; (b) granulometry distribution of the powders.

All the samples were fabricated by adopting the standard process parameters provided by EOS for this alloy. They are summarized in Table 2.

Table 2. Process parameters employed for all samples.

\begin{tabular}{cc}
\hline \multicolumn{2}{c}{ Process Parameters } \\
\hline Layer thickness & $30 \mu \mathrm{m}$ \\
Laser power & $340 \mathrm{~W}$ \\
Focal spot dimension & $0.1 \mathrm{~mm}$ \\
Scanning speed & $1250 \mathrm{~mm} / \mathrm{s}$ \\
Table temperature & $160^{\circ} \mathrm{C}$ \\
Hatch spacing & $0.12 \mathrm{~mm}$ \\
\hline
\end{tabular}

The samples geometry employed for the present study is dog-bone, with a square cross-section. Nominal dimensions were chosen according to the standard [30], referring to sintered parts, not being available at present a specific standard for additive manufactured components. The selected geometry has a nominal gauge length of $25.40 \mathrm{~mm}$ and a cross-section of $5.72 \times 4.00 \mathrm{~mm}^{2}$ (Figure 2).

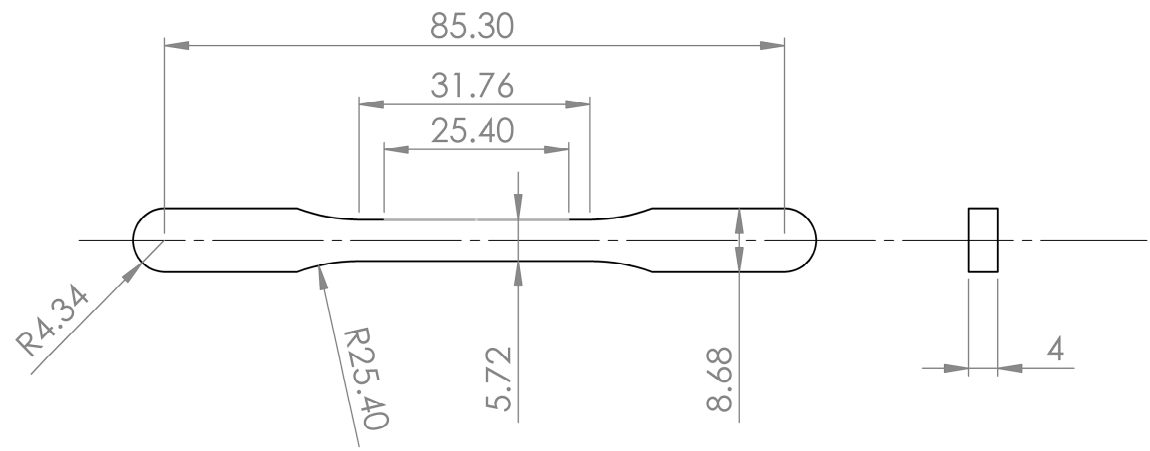

Figure 2. Dog-bone specimen geometry according to the ASTM E8/E8M-04 standard.

The first batch of nine specimens was fabricated with three different orientations: vertical, horizontal and inclined of $45^{\circ}$, with respect to the building plate. Out of them, 2 sets of 3 specimens (each one with the three different orientations) were processed by 2 different BF conditions; meanwhile, the remaining 3 samples were not postprocessed at all. Indeed, the tests along different orientations were also intended to provide a verification of a substantial isotropy of the alloy, coherently with what is reported by the EOS Ti6Al4V datasheet [31], in which very similar yield stresses (945 and $965 \mathrm{MPa})$ and ultimate tensile strengths (1055 and $1075 \mathrm{MPa}$ ) are declared for the horizontal and vertical building directions, with the percentage differences falling below $2 \%$. Analogous properties were also found by other authors [32-35], who used recent EOS SLM machines, as the one of this research. 
In these studies, the differences in terms of ultimate strength between the different orientations were within $4 \%$. More marked differences can be observed if less-modern machines are used for specimen production, instead, as documented by other works in the literature. These first 9 samples were thus subjected to tensile tests, and the results, which are presented in the following Section 3 , in terms of the load-displacement and stress-strain curves, confirmed that this alloy, processed via SLM with the parameters recommended by EOS $\mathrm{GmbH}$, can reasonably be regarded as isotropic. Consequently, the second batch of 30 samples was fabricated only along the vertical direction, using the same process parameters as the first batch; all the specimens were then heat-treated with 3 temperatures, at different durations (for each heat treatment and heating time, three repetitions were tested). In summary, overall, 39 specimens were studied: 3 were not postprocessed, 6 underwent BF and 30 were subjected to heat treatments.

The barrel finishing was selected as the surface-finishing operation for its flexibility and easiness to use, while for the heat treatments, different heating cycles were selected, starting from the treatment suggested by the powder supplier [31] and exploring possible alternative toward lower temperatures, to save energy and money in actual applications.

The barrel finishing was carried out, using a Rotar EMI 47, an industrial inclined octagonal barrel $400 \mathrm{~mm}$ in diameter moved by an asynchronous motor with electronic speed control. The employed media were cylinders made of a synthetic resin matrix with abrasive consisting of powder of alumina, silica and silicon carbide. They measure $15 \mathrm{~mm}$ in diameter and $25 \mathrm{~mm}$ in height and are angled cut (Figure 3a). The rotational speed and the filling percentage were chosen according to the analysis of the Bed Behavior (BB) diagram obtained following the methodology described in [23]. The BB diagram for this experimentation is reported in Figure $3 \mathrm{~b}$. The finishing process was performed at two different rotational speeds, in the rolling and cascading domains, respectively. Namely, the chosen rotational speeds were 30 and $42 \mathrm{rpm}$, while the filling percentage of the barrel was set at $50 \%$, according to the assessment that, at this value, the active layer has the greatest surface [36].
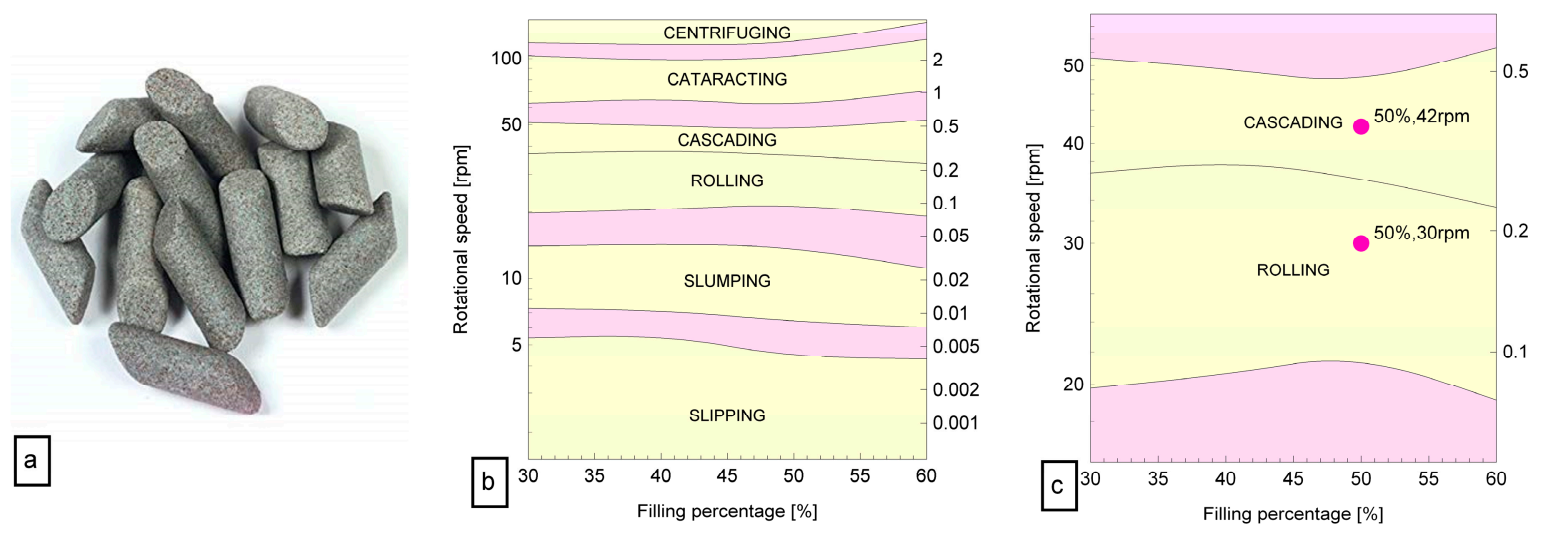

Figure 3. (a) Used media; (b) Bed Behavior (BB) diagram for the experimented charge; (c) zoom of the $\mathrm{BB}$ diagram and indication of the chosen process parameters.

The conditioned surfaces were analyzed through an Olympus SZH microscope and measured by a Mitutoyo Surftest SJ-412. The roughness profiles were achieved over a 12.5 measuring length and evaluated over $10 \mathrm{~mm}$, according to [37] indications. A spline profile filter with a $2.5 \mathrm{~mm}$ cutoff and an $8 \mu \mathrm{m}$ short wavelength cutoff was applied to data, in accordance with [38]. Three-dimensional maps $5 \times 3 \mathrm{~mm}^{2}$ were acquired for overall analysis of BF conditioning.

The heat treatment recommended by the M290 EOS material datasheet is $4 \mathrm{~h}$, at $800{ }^{\circ} \mathrm{C}$ [31]. The authors started from that suggested cycle and selected three alternative lower temperatures for the heat treatments: 482,704 and $788^{\circ} \mathrm{C}$. Higher temperatures are associated to more marked effects on Ti6Al4V; nevertheless, the study of the effect of low-temperature treatments is not unusual and can also be found in the literature $[32,39,40]$. Thus, the temperature-range choice was basically made to 
fulfill the industrial needs of time reduction and energy saving of the postprocessing phase, and it was limited by the operating characteristics of the facilities usually available in the industry. Moreover, the same reasoning was followed to select the durations: for each temperature, three heating durations were applied, trying to mediate between effectiveness and time. All the thermal treatments were carried out, using a Nabertherm LH120/14 electric furnace, at atmospheric pressure.

Table 3 reports all the produced samples, along with their orientation, actual dimensions and the type of applied postprocessing. All tensile tests were performed by using a servo-hydraulic MTS universal testing machine, capable of a tensile/compressive load up to $250 \mathrm{kN}$, with $150 \mathrm{~mm}$ of maximum stroke. Figure 4 shows some details of the experimental setup. All tests were performed under quasi-static loading conditions, imposing a ramped displacement at a run rate of $0.05 \mathrm{~mm} / \mathrm{min}$, according to the (ASTM E8/E8M-04) standard. An external extensometer was used, with a base length of $25 \mathrm{~mm}$. Crosshead displacement, axial load and specimen gauge section elongation coming from the extensometer were recorded during runs.
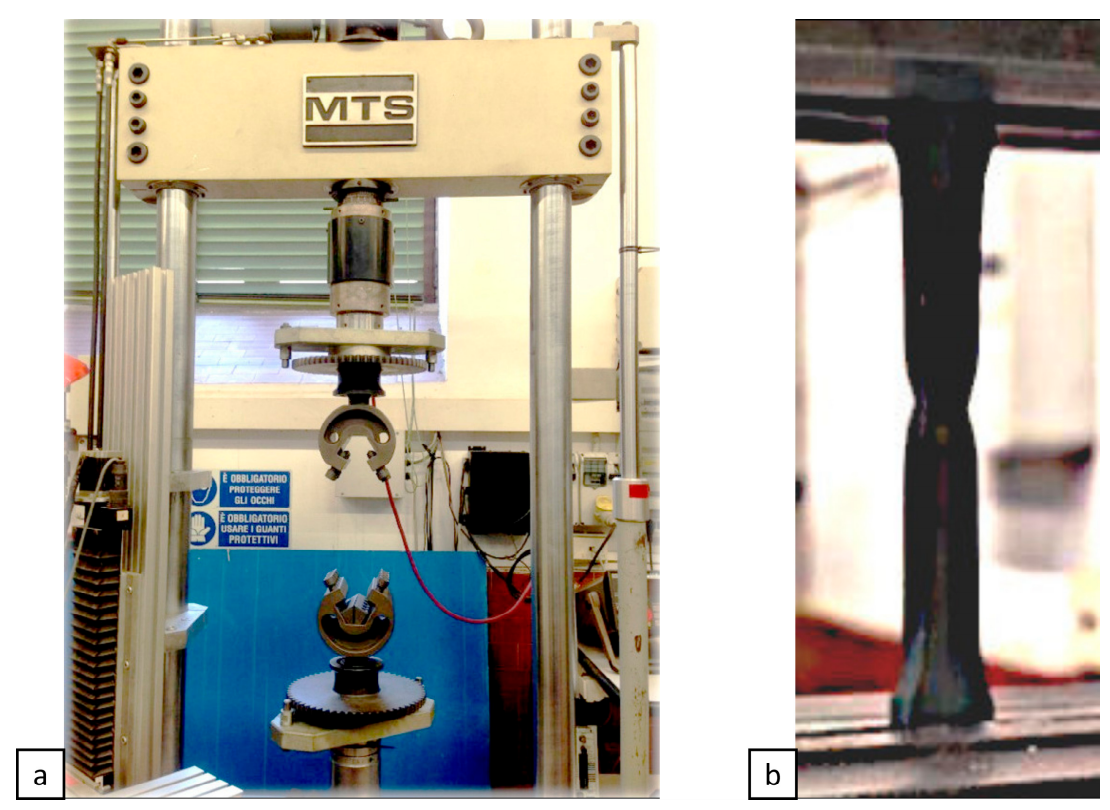

Figure 4. Experimental setup: (a) universal testing machine; (b) necked specimen just before fracture.

The cross-section of each specimen, uniform and rectangular, was measured, using a Mitutoyo micrometer, by taking three couples of width and thickness at different positions along the axial direction of the gauge section. A very low scatter, in the range of $+-0.02 \mathrm{~mm}$, was observed. At the end, the averages of the measurements were considered as the actual values of the cross-section dimensions.

Conversely, to measure the cross-section reduction and consequently have a qualitative estimation about the ductility, some fractured samples were digitized, using a structured light 3D scanner. A GOM Atos Core 300 was employed, being capable of accuracy up to $30 \mu \mathrm{m}$, and having a working volume of $300 \times 230 \times 400 \mathrm{~mm}^{3}$ and a blue light fringes projector, making the acquisition process almost insensitive to ambient-light interference. 
Table 3. Specimens IDs, actual dimensions and postprocessing information.

\begin{tabular}{|c|c|c|c|c|c|}
\hline Specimen ID & $\begin{array}{c}\text { Gauge Section } \\
\text { Width (W) } \\
(\mathrm{mm})\end{array}$ & $\begin{array}{c}\text { Gauge Section } \\
\text { Thickness (T) } \\
\text { (mm) }\end{array}$ & $\begin{array}{c}\text { Fabrication } \\
\text { Direction }\end{array}$ & $\begin{array}{c}\text { Heat } \\
\text { Treatment }\end{array}$ & $\begin{array}{c}\text { Barrel } \\
\text { Finishing }\end{array}$ \\
\hline BF 0000 & 5.74 & 4.08 & Horizontal & - & - \\
\hline BF 0045 & 5.58 & 3.94 & Diagonal & - & - \\
\hline BF 0090 & 5.54 & 3.77 & Vertical & - & - \\
\hline BF 3000 & 5.30 & 3.84 & Horizontal & - & $30 \mathrm{rpm}$ \\
\hline BF 3045 & 5.30 & 3.80 & Diagonal & - & $30 \mathrm{rpm}$ \\
\hline BF 3090 & 5.40 & 3.64 & Vertical & - & $30 \mathrm{rpm}$ \\
\hline BF 4200 & 5.30 & 3.80 & Horizontal & - & $42 \mathrm{rpm}$ \\
\hline BF 4245 & 5.30 & 3.74 & Diagonal & - & $42 \mathrm{rpm}$ \\
\hline BF 4290 & 5.30 & 3.60 & Vertical & - & $42 \mathrm{rpm}$ \\
\hline TT 482061 & 5.75 & 4.03 & Vertical & $482{ }^{\circ} \mathrm{C}-6 \mathrm{~h}$ & - \\
\hline TT 482062 & 5.77 & 4.02 & Vertical & $482^{\circ} \mathrm{C}-6 \mathrm{~h}$ & - \\
\hline TT 482063 & 5.76 & 4.06 & Vertical & $482{ }^{\circ} \mathrm{C}-6 \mathrm{~h}$ & - \\
\hline TT 482081 & 5.76 & 4.04 & Vertical & $482{ }^{\circ} \mathrm{C}-8 \mathrm{~h}$ & - \\
\hline TT 482082 & 5.78 & 4.02 & Vertical & $482{ }^{\circ} \mathrm{C}-8 \mathrm{~h}$ & - \\
\hline TT 482083 & 5.77 & 4.08 & Vertical & $482{ }^{\circ} \mathrm{C}-8 \mathrm{~h}$ & - \\
\hline TT 482101 & 5.76 & 4.02 & Vertical & $482^{\circ} \mathrm{C}-10 \mathrm{~h}$ & - \\
\hline TT 482102 & 5.76 & 4.03 & Vertical & $482^{\circ} \mathrm{C}-10 \mathrm{~h}$ & - \\
\hline TT 482103 & 5.79 & 4.03 & Vertical & $482^{\circ} \mathrm{C}-10 \mathrm{~h}$ & - \\
\hline TT 704041 & 5.79 & 4.05 & Vertical & $704{ }^{\circ} \mathrm{C}-4 \mathrm{~h}$ & - \\
\hline TT 704042 & 5.76 & 4.03 & Vertical & $704{ }^{\circ} \mathrm{C}-4 \mathrm{~h}$ & - \\
\hline TT 704043 & 5.79 & 4.04 & Vertical & $704^{\circ} \mathrm{C}-4 \mathrm{~h}$ & - \\
\hline TT 704051 & 5.76 & 4.05 & Vertical & $704^{\circ} \mathrm{C}-5 \mathrm{~h}$ & - \\
\hline TT 704052 & 5.78 & 4.05 & Vertical & $704{ }^{\circ} \mathrm{C}-5 \mathrm{~h}$ & - \\
\hline TT 704053 & 5.80 & 4.03 & Vertical & $704^{\circ} \mathrm{C}-5 \mathrm{~h}$ & - \\
\hline TT 704061 & 5.77 & 4.02 & Vertical & $704^{\circ} \mathrm{C}-6 \mathrm{~h}$ & - \\
\hline TT 704062 & 5.79 & 4.04 & Vertical & $704^{\circ} \mathrm{C}-6 \mathrm{~h}$ & - \\
\hline TT 704063 & 5.76 & 4.04 & Vertical & $704^{\circ} \mathrm{C}-6 \mathrm{~h}$ & - \\
\hline TT 788031 & 5.78 & 4.04 & Vertical & $788^{\circ} \mathrm{C}-3 \mathrm{~h}$ & - \\
\hline TT 788032 & 5.81 & 4.03 & Vertical & $788^{\circ} \mathrm{C}-3 \mathrm{~h}$ & - \\
\hline TT 788033 & 5.80 & 4.02 & Vertical & $788^{\circ} \mathrm{C}-3 \mathrm{~h}$ & - \\
\hline TT 788041 & 5.80 & 4.02 & Vertical & $788^{\circ} \mathrm{C}-4 \mathrm{~h}$ & - \\
\hline TT 788042 & 5.78 & 3.99 & Vertical & $788^{\circ} \mathrm{C}-4 \mathrm{~h}$ & - \\
\hline TT 788043 & 5.78 & 4.03 & Vertical & $788^{\circ} \mathrm{C}-4 \mathrm{~h}$ & - \\
\hline TT 788051 & 5.77 & 4.02 & Vertical & $788^{\circ} \mathrm{C}-5 \mathrm{~h}$ & - \\
\hline TT 788052 & 5.76 & 4.06 & Vertical & $788^{\circ} \mathrm{C}-5 \mathrm{~h}$ & - \\
\hline TT 788053 & 5.79 & 4.03 & Vertical & $788^{\circ} \mathrm{C}-5 \mathrm{~h}$ & - \\
\hline TT 800041 & 5.86 & 4.04 & Vertical & $800{ }^{\circ} \mathrm{C}-4 \mathrm{~h}$ & - \\
\hline TT 800042 & 5.85 & 4.02 & Vertical & $800{ }^{\circ} \mathrm{C}-4 \mathrm{~h}$ & - \\
\hline TT 800043 & 5.87 & 4.01 & Vertical & $800{ }^{\circ} \mathrm{C}-4 \mathrm{~h}$ & - \\
\hline
\end{tabular}

Each half of the barrel-finished samples, after the tensile test, was measured with the scanner, and the resulting point cloud was processed in three subsequent stages. First, the overall 3D geometry was reconstructed (Figure 5a), and then multiple cross-sections were isolated along the specimen axis, at fixed steps of $0.5 \mathrm{~mm}$, using the software GOM Inspect. Afterward, the sections' perimeters were identified and exported as closed loops (see Figure $5 b$ ), and finally postprocessed by using a MATLAB custom-made routine to compute the area enclosed by the loops. Due to the irregular shape of the fracture, the section closest to the fracture (red) was discarded, and the next section (green) was considered for surface computation, as schematically shown in Figure 5b. The area of the last acceptable deformed section was then compared to the corresponding undeformed one, measured with the micrometer and reported in Table 3, to compute the percentage of area reduction at fracture, presented in the following Section 3. 

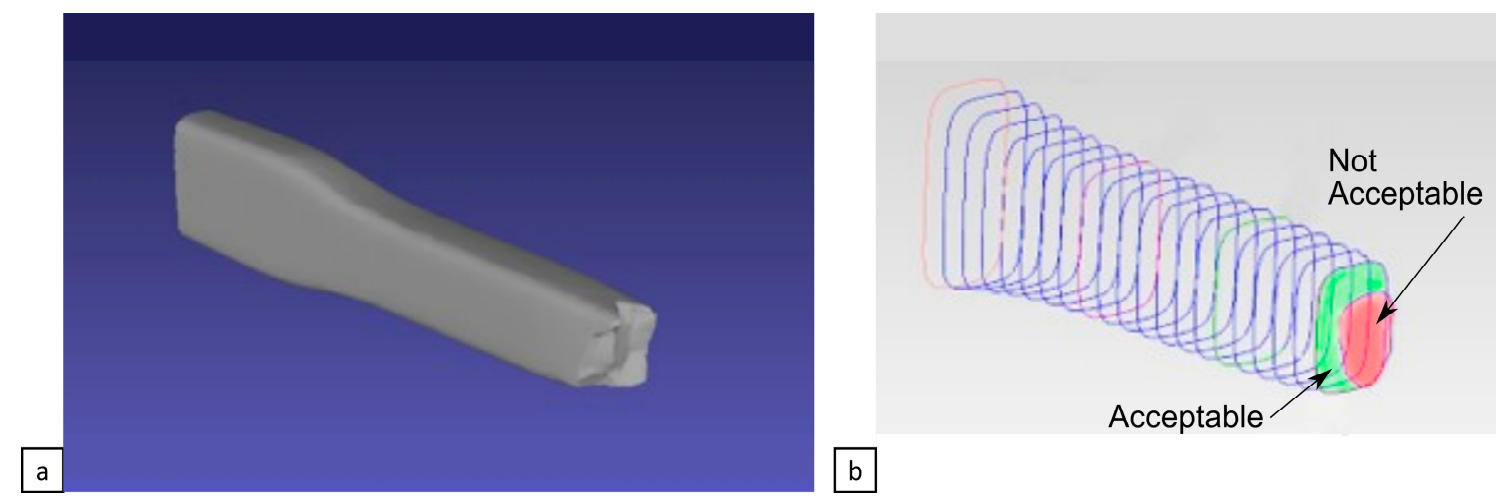

b

Figure 5. Example of cross-section measurement, using the 3D structured light scanner: (a) acquired and reconstructed 3D shape; (b) cross-sections evaluated through a MATLAB routine.

\section{Results}

The results of the experimental campaign are reported in Figures 6-13. Figure 6 shows the surface macrographies of specimens before and after BF. The untreated surfaces are characterized by several defects, as expected. The horizontal one ( $0^{\circ}$ orientation) shows the effect of laser processing, and the tracks are visible. The $45^{\circ}$ specimen is affected by the so-called balling phenomenon, which is more evident in $90^{\circ}$ one. As the $\mathrm{BF}$ is performed at $30 \mathrm{rpm}$, these defects are deeply reduced: The laser tracks disappeared, and only some local asperities are present. At $42 \mathrm{rpm}$, the BF action is more effective, and almost all the defects are removed.

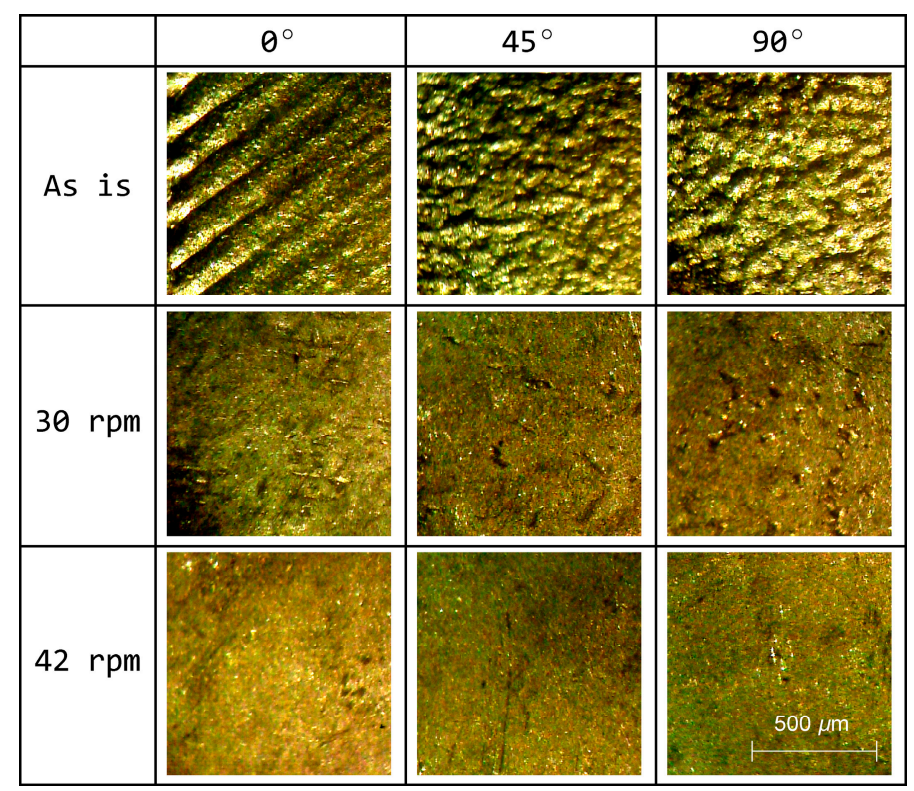

Figure 6. Macrographies before and after barrel finishing (BF). 

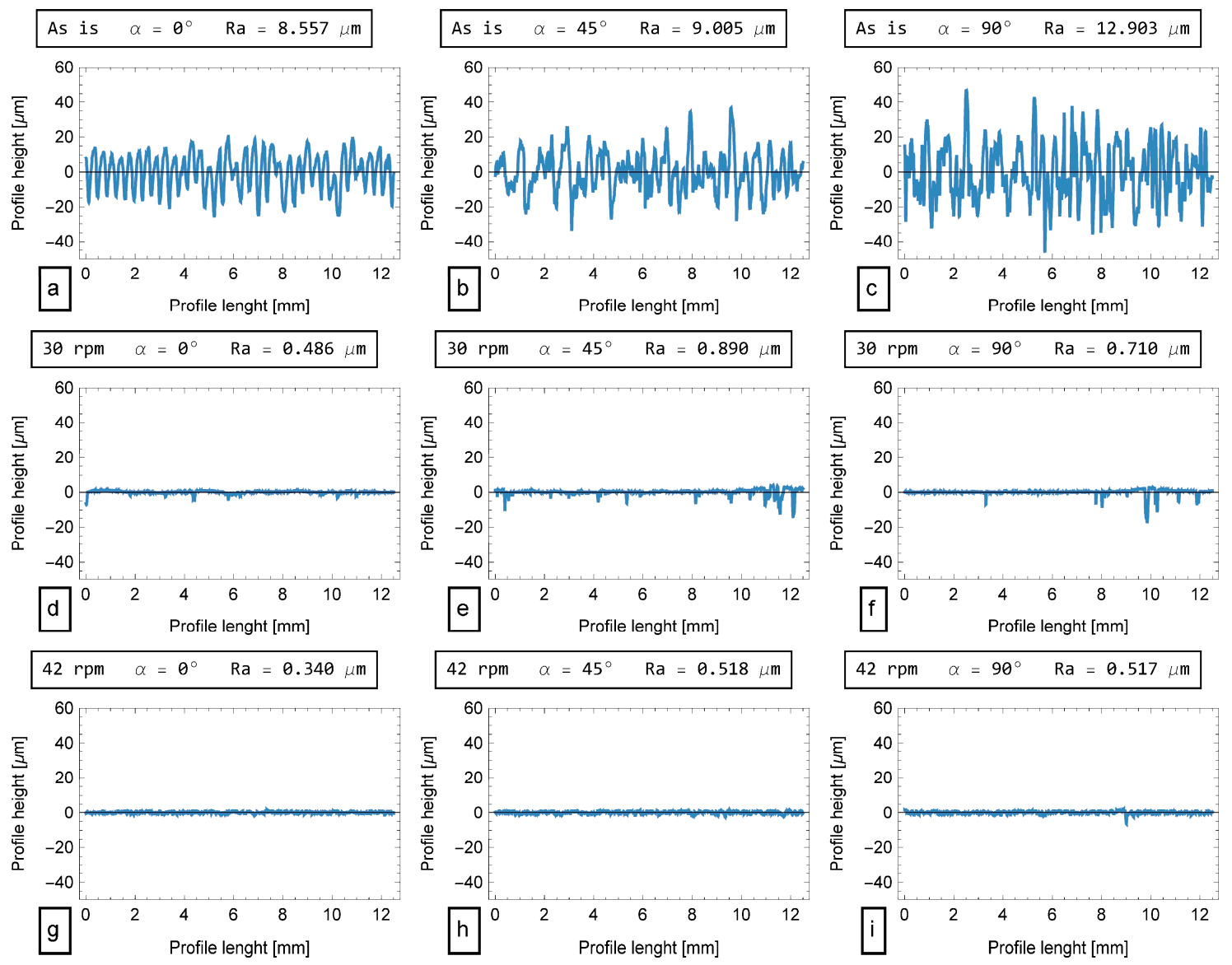

Figure 7. Roughness profiles for investigated specimen orientations before BF conditioning $(\mathbf{a}, \mathbf{b}, \mathbf{c})$ after $\mathrm{BF}$ at $30 \mathrm{rpm}(\mathbf{d}, \mathbf{e}, \mathbf{f})$ and after $42 \mathrm{rpm}(\mathbf{g}, \mathbf{h}, \mathbf{i})$.

This morphological investigation can be quantitatively analyzed by roughness measurements. Before the conditioning, the expected profiles are observed. An almost periodical behavior is present for $0^{\circ}$ orientation: Since the laser is orthogonally consolidating the area, no staircase effect and reduced balling phenomenon occur; as a consequence, the hatching laser tracks are prominent (Figure 7a). In this case, the average roughness $\mathrm{Ra}$ is low and equal to $8.557 \mu \mathrm{m}$, and the total roughness, namely the distance between the maximum peak and the deepest valley, is $40 \mu \mathrm{m}$. At $45^{\circ}$ orientation (Figure $7 \mathrm{~b}$ ), the staircase and balling phenomenon affect the surface, which shows a greater Ra and Rt. For $90^{\circ}$ orientation, the defects are pronounced with a Rt about twice the $0^{\circ}$ case and an Ra equal to 12.903 $\mu \mathrm{m}$ (Figure $7 \mathrm{c}$ ). The conditioning via BF at $30 \mathrm{rpm}$ markedly reduces the previous defects, providing surfaces with less than $1 \mu \mathrm{m}$ Ra: Only some scratches of $5 \mu \mathrm{m}$ maximum height are present in $0^{\circ}$ orientation, as shown in Figure 7d; deeper valleys, $10 \mu \mathrm{m}$ height, are present in $45^{\circ}$ and $90^{\circ}$ surfaces (Figure $7 \mathrm{e}$ and $\mathrm{f}$ ). When BF at $42 \mathrm{rpm}$ is adopted, the previous scratches are almost removed and a Ra of about $0.5 \mu \mathrm{m}$ is reached (Figure $7 \mathrm{~g}-\mathrm{i}$ ). It is well evident that BF is able to delete the micro-geometrical feature SLM technique applied to the fabricated surfaces. 

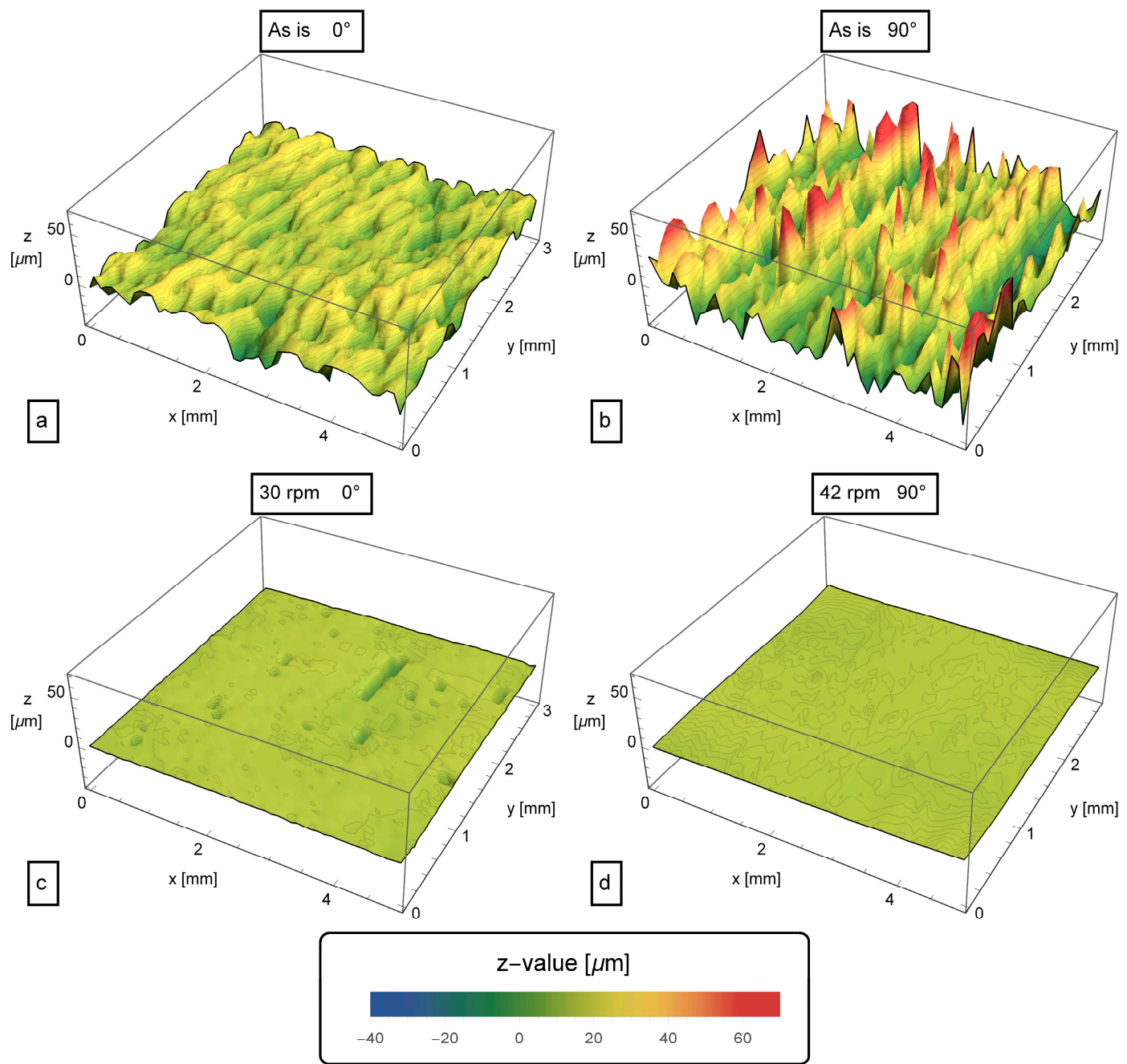

Figure 8. Three-dimensional maps of untreated $0^{\circ}(\mathbf{a})$ and $90^{\circ}(\mathbf{b})$ specimen surfaces, $30 \mathrm{rpm}(\mathbf{c})$ and 42 rpm (d) BF-conditioned surfaces.
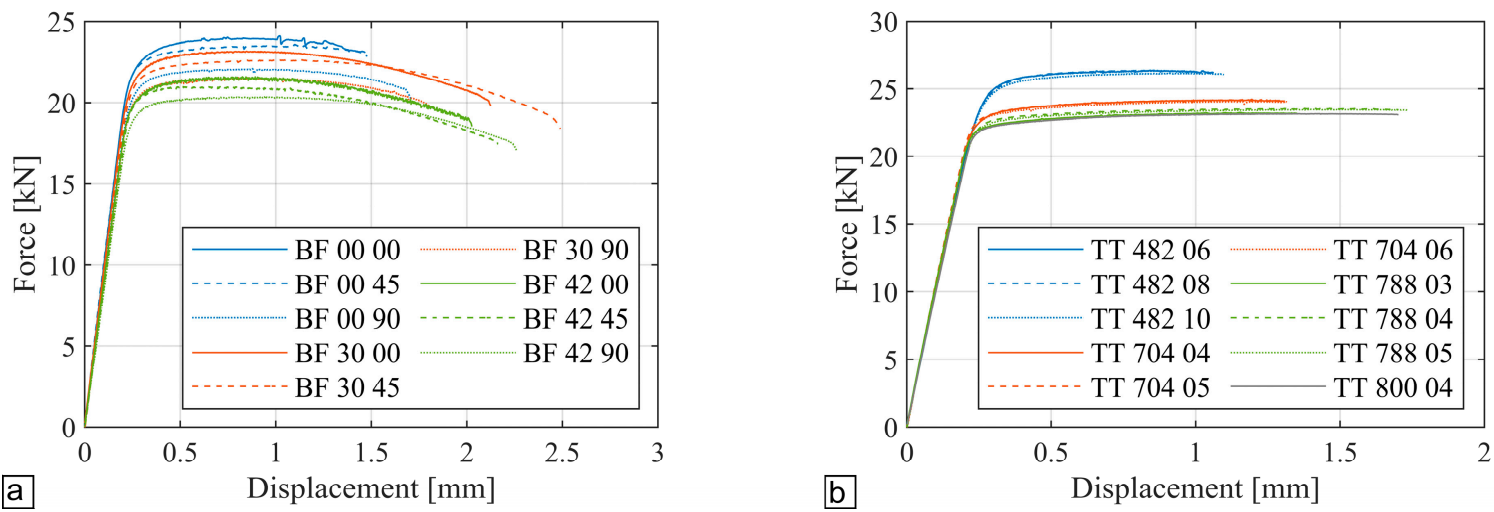

Figure 9. Force-displacement curves for (a) the barrel-finished samples and (b) the heat-treated samples. 

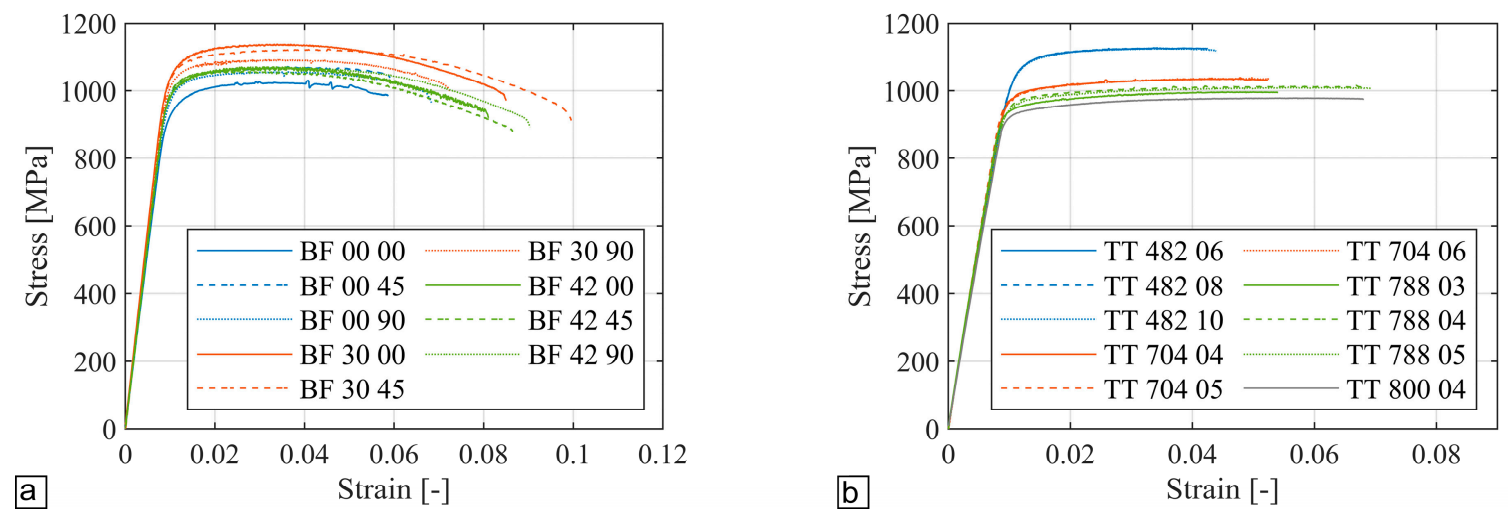

Figure 10. Stress-strain curves for (a) the barrel-finished samples and (b) the heat-treated samples.
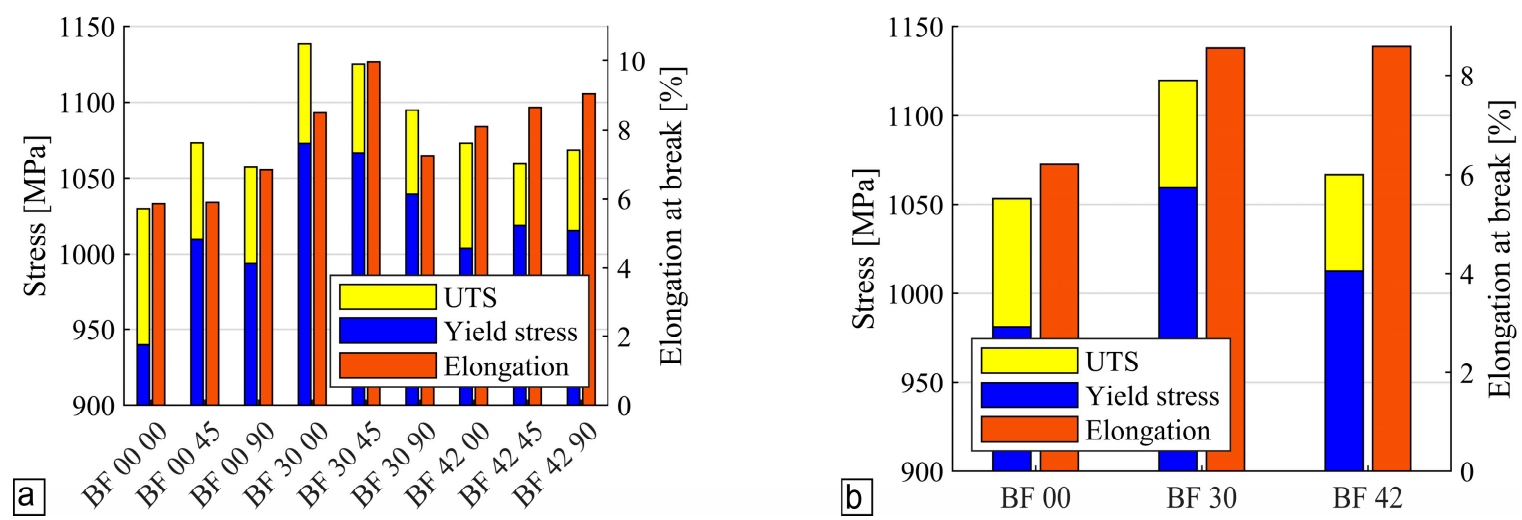

Figure 11. (a) Yield stress, ultimate tensile strength and elongation at break of the barrel-finished samples; (b) same quantities averaged over the BF speeds.
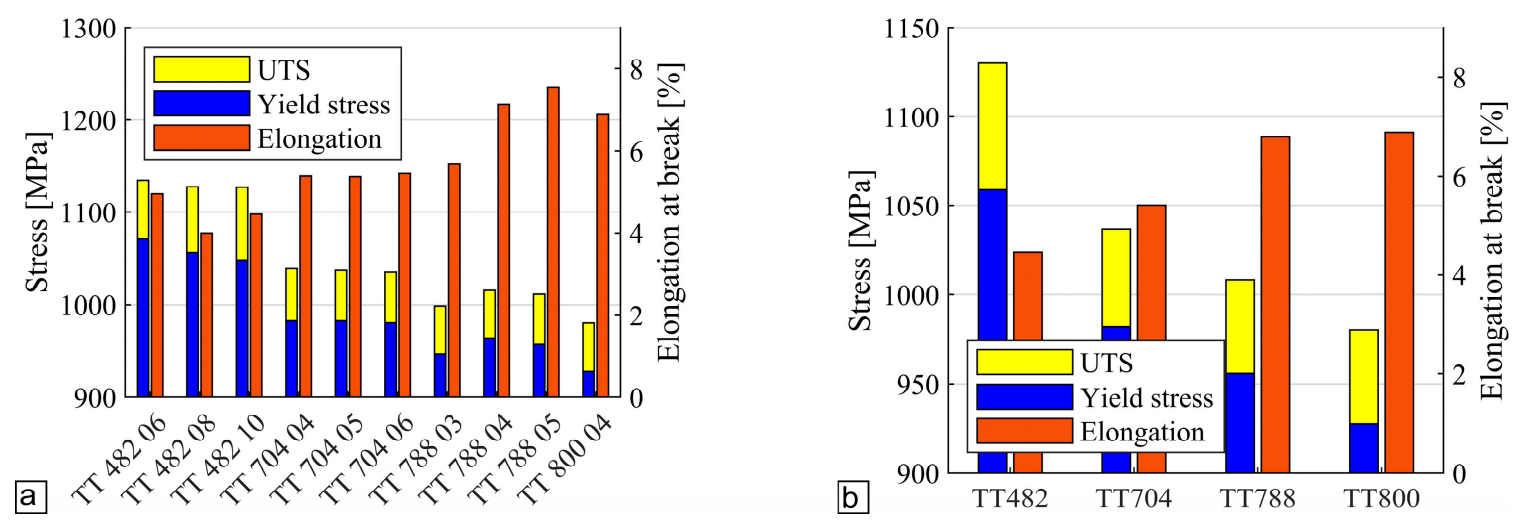

Figure 12. (a) Yield stress, ultimate tensile strength and elongation at break for the heat-treated samples; (b) same quantities averaged over the postprocessing temperature. 


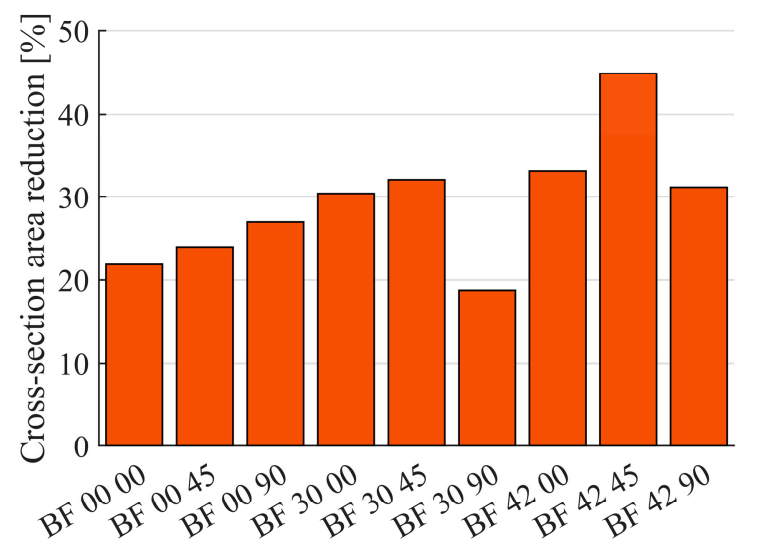

Figure 13. Area reduction (\%) measured with the 3D scanner on fractured samples.

An overall analysis of surface was carried out by 3D maps. The unconditioned $0^{\circ}$ surface is almost periodical but some subsidence zones present (in dark green in Figure 8a). A BF treatment at $30 \mathrm{rpm}$ is a delicate operation which is able to delete the previous behavior but some little zones are characterized by local valleys, probably reminiscence of initial deepest subsidence (Figure 8c). Conversely the chaotic and rough surface related to $90^{\circ}$ orientation shown in Figure $8 \mathrm{~b}$ is completely flattened by a $42 \mathrm{rpm}$ BF action which removed any defects present at the beginning (Figure $8 \mathrm{~d}$ ).

Figure 9 summarizes the overall behavior, in terms of force-displacement curves, of barrel-finished and heat-treated samples. For the BF (Figure 9a), only one sample was tested for each combination of building direction and finishing intensity, while for the thermally treated specimens, the median value of three repetitions was reported in Figure $9 \mathrm{~b}$.

Figure 10 shows the corresponding engineering stress-strain curves for barrel-finished and heat-treated specimens, respectively, calculated using the actual specimen dimensions measured before the tests.

The barrel-finished samples exhibited a maximum scatter below $15 \%$ in terms of yielding stress, while the thermal-treated specimens showed an improved behavior in terms of repeatability, with the only exception being the samples treated at $482{ }^{\circ} \mathrm{C}$ (TT 482), with a significantly higher yielding value. Their yielding stress, higher than $1050 \mathrm{MPa}$, resulted in being comparable to that of the barrel-finished samples, which did not receive any thermal treatment.

Conversely, both the elongation at break and ultimate tensile strength demonstrated a higher scatter due to the influence by the postprocesses. Their values are reported in Figures 11a and 12a. In this case, for the heat-treated specimens, the mean values of the three repetitions are used. In Figures $11 \mathrm{~b}$ and $12 \mathrm{~b}$, the mean values of ultimate tensile strength, yield stress and elongation at break are summed up for each level of surface finish and each temperature.

Finally, the percentage of area reduction at fracture of the barrel-finished specimens, evaluated close to the most critical section, is illustrated in Figure 13.

\section{Discussion}

The tensile tests exhibited a good level of repeatability, in terms of yield stress, elastoplastic behavior and ultimate tensile strength. Moreover, the repetitions for each heat-treatment level turned out to be matching perfectly, confirming the consistency of the building and postconditioning processes. Negligible effects were observed in the mechanical behavior due to fabrication orientation, which essentially excludes the possibility of macroscopic structural anisotropy induced by the production process. Likewise, the surface finish had moderate effects on yielding stress and ultimate tensile strength, with differences below $15 \%$ overall. Conversely, the heat-treatments showed a systematic impact both on yield stress and ultimate tensile strength, lowering those values by about $7 \%$. Only the 
samples cured at $482{ }^{\circ} \mathrm{C}$ revealed a yield stress comparable to that typical of untreated samples (around $1050 \mathrm{MPa})$.

All the postprocess treatments had a significant influence on the elongation at break. Both the barrel-finished samples' subsets exhibited an increased fracture elongation of about $25 \%$, while the heat-treatments enhanced the elongation, with respect to their intensity, up to more than $30 \%$. Eventually, the area reduction also showed an increasing trend with the increase of BF velocity.

The influence on the ductility of surface finish condition can be interpreted as the effect of high surface roughness, typical of as-built specimens, which might act as a crack initiator. Such roughness, typically in the range of $\mathrm{Ra}=5-15 \mu \mathrm{m}$ [23], can be regarded as a series of superficial defects, causing a stress intensification in some spots on the surface of the sample, which in turn produce a premature fracture. The interpretation is that, when the first fracture appears, the stress distribution is not yet the typical one of tensile specimens, in which the critical point, where the deformation should be localized, is known to be the one in the middle of the cross-section. Thus, at fracture onset, the expected critical point inside is not more critical than other points on the surface, where conversely the fracture can be triggered by superficial defects causing a local stress intensification.

To support these hypotheses, a numerical simulation of a tensile test was performed to assess the plastic strain at the fracture onset. The simulation was carried out, using the commercial finite-element analysis code ANSYS. The material was regarded as isotropic and described with a nonlinear stress-strain law, based on Voce's formulation. The specimen was discretized, using solid elements with quadratic formulation with an average element length of $0.1 \mathrm{~mm}$. All the possible symmetries were exploited in the modeling, in order to reduce the number of elements required. Surface roughness and residual stresses were neglected.

The results, which are reported in Figure 14, show how the total equivalent plastic strain exhibits a nearly homogeneous distribution along the cross-section, showing only a marginal concentration in the inner area. Such behavior suggests that the first failure occurs before reaching a localization of deformation inside the specimen, as observed, for instance, on standard material. Thus, being inner and outer points of the sample at the same stress level, the fracture is supposed to start outside, triggered by superficial defects or residual stresses.

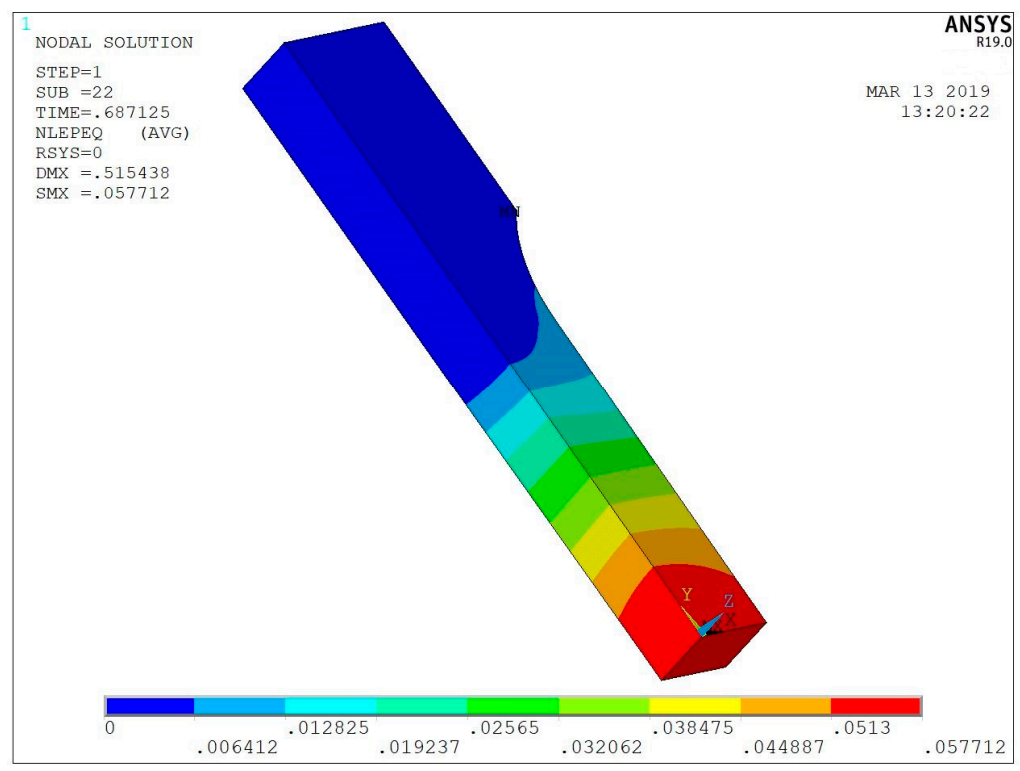

Figure 14. Total equivalent plastic strain distribution in the specimen at the time of fracture.

Finally, besides the modification of the microstructure, the contribution of heat treatments to ductility enhancement can be explained with the attenuation of residual stresses, induced by the fabrication process. The residual stresses, being mainly concentrated on the samples' surface, 
alter the expected stress distribution, hence triggering an untimely fracture onset as for the case of surface roughness.

\section{Conclusions}

A thorough static mechanical characterization of AM SLM Ti6Al4V was performed, highlighting the influence of different thermal treatments and surface finish on the resulting mechanical performance. Samples were subjected alternatively to BF of different intensities or thermal treatments at different temperatures and durations. Samples were successively subjected to tensile tests under quasi-static conditions. Fracture surfaces and area reduction were additionally evaluated on fractured specimens.

According to experimental evidence, the building direction seemed to not affect the mechanical performance of additive Ti6Al4V significantly, such that the alloy can be reasonably regarded as isotropic. The longer the duration of the heat treatment, the more ductile the observed material behavior was. Analogously, the more intense the BF was, the higher the elongation at fracture was. Both postprocesses can play a key role in the trade-off between strength and ductility, having the great advantage of being simple to perform.

The thermal treatments seemed to be more suitable when the ultimate tensile strength was not of primary importance and a specific microstructure must be obtained. The experimental results pointed out that a temperature of $788^{\circ} \mathrm{C}$ seemed to be the best choice to increase ductility without compromising strength. On the other hand, BF proved to be effective in enhancing elongation at fracture, with a marginal influence on other mechanical properties. Within the two intensities tested in the present work, the one corresponding to $30 \mathrm{rpm}$ rotational speed gave the most beneficial results.

Author Contributions: Data curation, F.N., L.B. and A.B.; Formal analysis, F.N.; Investigation, L.B., A.B. and L.C.; Methodology, F.N., L.B., A.B. and L.C.; Supervision, A.B., L.C. and F.V.; Writing-original draft, F.N., L.B. and L.C.; Writing-review \& editing, F.N. and L.B.. All authors have read and agreed to the published version of the manuscript.

Funding: This research did not receive any specific grant from funding agencies in the public, commercial or not-for-profit sectors.

Acknowledgments: The authors wish to thank Eng. Luciano Macera for the specimens' fabrication.

Conflicts of Interest: The authors declare no conflict of interest.

\section{References}

1. Milewski, J.O. Additive Manufacturing of Metals; Springer: Berlin, Germany, 2017; ISBN 9783319582047.

2. ISO/ASTM 52900-15 Standard Terminology for Additive Manufacturing—General Principles_Terminology 2015; ISO: Geneva, Switzerland, 2015.

3. Donachie, M.J. Titanium: A Technical Guide; ASM International: Materials Park, OH, USA, 1988; ISBN 0.87170-309-2.

4. Lütjering, G. Influence of processing on microstructure and mechanical properties of $(\alpha+\beta)$ titanium alloys. Mater. Sci. Eng. A 1998, 243, 32-45. [CrossRef]

5. Sieniawski, J.; Ziaja, W.; Kubiak, K.; Motyk, M. Microstructure and Mechanical Properties of High Strength Two-Phase Titanium Alloys. In Titanium Alloys-Advances in Properties Control; IntechOpen Limited: London, UK, 2013.

6. Ritchie, R.O.; Davidson, D.L.; Boyce, B.L.; Campbell, J.P.; Roder, O. High-cycle fatigue of Ti-6Al-4V. Fatigue Fract. Eng. Mater. Struct. 1999, 22, 621-631. [CrossRef]

7. Cortese, L.; Nalli, F.; Broggiato, G.B.; Coppola, T. An effective experimental-numerical procedure for damage assessment of Ti6Al4V. In Proceedings of the SEM Annual Conference and Exposition on Experimetal and Applied Mechanics, Hilton Orange County, Costa Mesa, CA, USA, 8-11 June 2015; In Proceedings of the Conference Proceedings of the Society for Experimental Mechanics Series. 2016; Volume 9, pp. 43-49.

8. Huang, R.; Riddle, M.; Graziano, D.; Warren, J.; Das, S.; Nimbalkar, S.; Cresko, J.; Masanet, E. Energy and emissions saving potential of additive manufacturing: The case of lightweight aircraft components. J. Clean. Prod. 2016, 135, 1559-1570. [CrossRef] 
9. Lütjering, G.; Williams, J.C. Titanium, 2nd ed.; Springer: Berlin, Germany, 2007; ISBN 978-3-540-71397-5.

10. Gu, D. Laser Additive Manufacturing of High Performance Materials; Springer: Berlin, Germany, 2015; ISBN 9783662460887.

11. Facchini, L.; Magalini, E.; Robotti, P.; Molinari, A.; Höges, S.; Wissenbach, K. Ductility of a Ti-6Al-4V alloy produced by selective laser melting of prealloyed powders. Rapid Prototyp. J. 2010, 16, 450-459. [CrossRef]

12. Ali, H.; Ma, L.; Ghadbeigi, H.; Mumtaz, K. In-situ residual stress reduction, martensitic decomposition and mechanical properties enhancement through high temperature powder bed pre-heating of Selective Laser Melted Ti6Al4V. Mater. Sci. Eng. A 2017, 695, 211-220. [CrossRef]

13. Xu, W.; Brandt, M.; Sun, S.; Elambasseril, J.; Liu, Q.; Latham, K.; Xia, K.; Qian, M. Additive manufacturing of strong and ductile Ti-6Al-4V by selective laser melting via in situ martensite decomposition. Acta Mater. 2015, 85, 74-84. [CrossRef]

14. Dutta, B.; Froes, F.H. Additive Manufacturing of Titanium Alloys: State of the Art, Challenges and Opportunities; Elsevier Inc.: Amsterdam, The Netherlands, 2016; ISBN 9780128047835.

15. Kazantseva, N.; Krakhmalev, P.; Yadroitsev, I.; Fefelov, A.; Merkushev, A.; Ilyinikh, M.; Vinogradova, N.; Ezhov, I.; Kurennykh, T. Oxygen and nitrogen concentrations in the Ti-6Al-4V alloy manufactured by direct metal laser sintering (DMLS) process. Mater. Lett. 2017, 209, 311-314. [CrossRef]

16. STM F2924-14 Standard Specification for Additive Manufacturing Titanium-6 Aluminum-4 Vanadium with Powder Bed Fusion; ASTM International: West Conshohocken, PA, USA, 2014.

17. ASTM F3001-14 Standard Specification for Additive Manufacturing Titanium-6 Aluminum-4 Vanadium ELI (Extra Low Interstitial) with Powder Bed Fusion; ASTM International: West Conshohocken, PA, USA, 2014.

18. Mercelis, P.; Kruth, J.P. Residual stresses in selective laser sintering and selective laser melting. Rapid Prototyp. J. 2006, 12, 254-265. [CrossRef]

19. Liu, Y.; Yang, Y.; Wang, D. A study on the residual stress during selective laser melting (SLM) of metallic powder. Int. J. Adv. Manuf. Technol. 2016, 87, 647-656. [CrossRef]

20. Parry, L.; Ashcroft, I.A.; Wildman, R.D. Understanding the effect of laser scan strategy on residual stress in selective laser melting through thermo-mechanical simulation. Addit. Manuf. 2016, 12, 1-15. [CrossRef]

21. Liu, S.; Shin, Y.C. Additive manufacturing of Ti6Al4V alloy: A review. Mater. Des. 2018, 164, 107552. [CrossRef]

22. Chan, K.S.; Koike, M.; Mason, R.L.; Okabe, T. Fatigue life of titanium alloys fabricated by additive layer manufacturing techniques for dental implants. Metall. Mater. Trans. A Phys. Metall. Mater. Sci. 2013, 44, 1010-1022. [CrossRef]

23. Boschetto, A.; Bottini, L.; Veniali, F. Surface roughness and radiusing of Ti6Al4V selective laser melting-manufactured parts conditioned by barrel finishing. Int. J. Adv. Manuf. Technol. 2018, 94, 2773-2790. [CrossRef]

24. Boschetto, A.; Bottini, L.; Veniali, F. Microremoval modeling of surface roughness in barrel finishing. Int. J. Adv. Manuf. Technol. 2013, 69, 2343-2354. [CrossRef]

25. Tulinski, E.H. Mass Finishing in: ASM Metals Handbook Vol.5. Surface Engineering, 9th ed.; ASM International: Materials Park, OH, USA, 1994; pp. 261-277.

26. Singh, R.; Singh, M. Surface roughness improvement of cast components in vacuum moulding by intermediate barrel finishing of fused deposition modelling patterns. Proc. Inst. Mech. Eng. Part E J. Process Mech. Eng. 2017, 231, 309-316. [CrossRef]

27. Gillespie, L.K. Deburring and Edge Finishing Handbook, 1st ed.; Society of Manufacturing Engineers: Dearborne, TX, USA, 1999; ISBN 0872635015.

28. Henein, H.; Brimacombe, J.K.; Watkinson, A.P. Experimental study of transverse bed motion in rotary kilns. Metall. Trans. B 1983, 14, 191-205. [CrossRef]

29. EOS GmbH Steel 17-4PH_Material Datasheet EOS M290; EOS GmbH: Krailling, Germany, 2016; Volume 49, pp. 1-4.

30. ASTM E8/E8M-04 Standard Test Methods for Tensile Testing of Metallic Materials; ASTM International: West Conshohocken, PA, USA, 2004. [CrossRef]

31. EOS GmbH Titanium Ti6Al4V—Material Data Sheet; EOS GmbH: Krailling, Germany, 2014; Volume 49, pp. 1-5.

32. Tao, P.; Li, H. xue; Huang, B. ying; Hu, Q. dong; Gong, S. li; Xu, Q. yan Tensile behavior of Ti-6Al-4V alloy fabricated by selective laser melting: Effects of microstructures and as-built surface quality. China Foundry 2018, 15, 243-252. [CrossRef] 
33. Rafi, H.K.; Karthik, N.V.; Gong, H.; Starr, T.L.; Stucker, B.E. Microstructures and mechanical properties of Ti6Al4V parts fabricated by selective laser melting and electron beam melting. J. Mater. Eng. Perform. 2013, 22, 3872-3883. [CrossRef]

34. Moletsane, M.G.; Yadroitsava, I.; Krakhmalev, P.; Yadroitsev, I. Tensile Properties and Microstructure of Standard Vertical and Horizontal DMLS Ti6Al4V (ELI) samples. Interim Interdiscip. J. 2016, 15, 133-140.

35. Mierzejewska, Z.A.; Hudák, R.; Sidun, J. Mechanical properties and microstructure of DMLS Ti6Al4V alloy dedicated to biomedical applications. Materials 2019, 12, 176. [CrossRef]

36. Cotell, C.M.; Sprague, J.A.; Smidt, F.A. ASM Handbook: Vol. 05 Surface Engineering; ASM International: Materials Park, OH, USA, 1994; ISBN 978-0871703842.

37. ISO 4287, Geometrical Product Specifications (GPS)—Surface Texture: Profile Method-Terms, Definitions and Surface Texture Parameters; International Organization for Standardization (ISO): Geneva, Switzerland, 1997.

38. ISO 16610-22, Geometrical Product Specifications (GPS)_Filtration_Part 22: Linear Profile Filters: Spline Filters; International Organization for Standardization (ISO): Geneva, Switzerland, 2015.

39. Vrancken, B.; Thijs, L.; Kruth, J.P.; Van Humbeeck, J. Heat treatment of Ti6Al4V produced by Selective Laser Melting: Microstructure and mechanical properties. J. Alloys Compd. 2012, 541, 177-185. [CrossRef]

40. Greitemeier, D.; Dalle Donne, C.; Schoberth, A.; Jürgens, M.; Eufinger, J.; Melz, T. Uncertainty of Additive Manufactured Ti-6Al-4V: Chemistry, Microstructure and Mechanical Properties. Appl. Mech. Mater. 2015, 807, 169-180. [CrossRef]

(C) 2020 by the authors. Licensee MDPI, Basel, Switzerland. This article is an open access article distributed under the terms and conditions of the Creative Commons Attribution (CC BY) license (http://creativecommons.org/licenses/by/4.0/). 